\title{
Political Commitment, Institutional Capacity and Urban Transport Governance Reform in Addis Ababa, Ethiopia
}

\author{
Yilak Akloweg \\ Lantern Institute of Data Science
}

\begin{abstract}
Following rapid urbanization, Ethiopia's capital city Addis Ababa has become circumscribed by a complex set of multipronged transport challenges that are a greatly contributing to its overall urban inefficiency. A lack of political commitment and weak institutional capacity among transportation sector leadership exacerbates this urban predicament. In these contexts, this paper examines the efficiency of the 2012 transport sector reform package initiated by Addis Ababa City Administration under mayor Diriba Kuma. Through this research, the roles played by (a lack of) political commitment and institutional capacity in the design, management and implementation the urban reform agenda are closely examined. To do so, the paper utilizes a Public Sector Governance (PSG) reform framework to analyze the interplay between political commitment to reform and institutional capacity to implement agreed reforms. In particular, the paper highlights the outcome of reforms in circumstances in which there is substantial political commitment but low institutional capacity. In this regard, to achieve better public policy outcomes the study identifes the need for dismantling unnecessary bureaucratic procedures as well as addressing inefficiencies in governing structures, coupled with revisiting and improving existing norms, rules and regulations in transport governance.
\end{abstract}

\section{BACKGROUND}

Good governance is critical in enhancing the development and management of the urban transport sector as a means to spurring economic growth and providing access to city residents. To meet this end, the Addis Ababa City Administration has passed different reform programs in its search for sustainable solutions to the rapidly urbanising metropolis but it has done so under conditions of limited resources amidst wider poverty. In such circumstances, transportation systems were elevated on the developmental policy agenda by the Mayor of the City in 2012. The move had wider support as other political parties accepted that failing to address such urban challenges could incite popular resentment similar to that which occurred following elections in the 1990 s.

Addis Ababa is the 125-year-old capital city of the second most populous nation in Africa, Ethiopia. Housing an official population of 4.5 million with an annual growth rate of $4 \%$, the city is estimated to contribute about $34 \%$ of the total GDP of the country. Like other developing cities in Africa, Addis Ababa has a very low per capita travel distance, ranging between 2-300 kilometres (Temesgen, 2007, p. 8). With this low mobility, forced walking accounts for about $65 \%$. The remaining $35 \%$ of mobility is covered by informal transport, light railway, public bus services and private cars. The transport challenges of Addis Ababa are multi-faceted and complex and are compounded by the longevity of their evolution, which makes tracing their origins and root causes more difficult. The most pressing problems are usually associated with poor transport infrastructure and traffic systems, and shortcomings in institutional capacity, including in planning and financial resources. In addition, the city remains susceptible to regular fatal road accidents, with a rate of 60 people per 10,000 vehicles (World Bank RPF, 2016).

The city's transport governance is characterized by a plethora of deficits, expressed in the form of poor land use and inappropriate implementation of economic development policies. The disintegration of villages and declining density associated with sprawl toward the peri-urban areas has also increased the travel distances and raised the price of public transport for commuters. As a result of such largely unplanned urban expansion, the City Administration has been compelled to allocate $25 \%$ of its annual budget $(2004-2010)^{2}$ to build new road and transport facilities, resulting in inadequate maintenance and upgrading of existing infrastructure .

This paper assesses the Urban Transport Reform of Addis Ababa initiated by Mayor Deriba and identifies the extent to which both political commitment and institutional capacity have been determining factors in poor transportation system outcomes Section 2 presents the political leadership challenge in historical perspective, before Section 3 outlines the reform process, including by reviewing relevant literature and outlining a framework for analyzing the interplay between political commitment and institutional capacity. Section 4 then examines transport system reform in Addis Ababa and assesses its impacts, before Section 5 provides a conclusion.

\footnotetext{
${ }^{1}$ The author wishes to thank the Volvo Research and Educational Foundation for the generous visiting fellowship award that initiated this research as part of TUT-POL project formed by the Graduate School of the Harvard School of Design and Planning.
}

2 Addis Ababa City Administration Budget Report, 2012 


\section{TRANSPORT GOVERNANCE IN HISTORICAL PERSPECTIVE}

The overt role played by politics in Addis Ababa's transportation system dates to the late 1890s, when then Emperor Minilik became fascinated by Western technology as well as the relationships between transportation infrastructure and military and political control over the heterogeneous regions of the Ethiopian Empire (Temesgen, 2007; Mattia, 2016). Minilik's successor as Emperor, Haile Selasse, instituted the Ministry of Public Transport and promoted a more structured approach to road building plans in the early 1920s. However, due to the Italian War of Aggression coupled with a lack of adequate financial resources and technical expertise, a number of these plans couldn't be implemented (Emmenegger, 2012, p.16). By 1942, Emperor Haile Selasse initiated a new chapter by institutionalizing the sector with the first transport codes and laws promulgated soon after the defeat of the occupying forces (Temesgen, 2007, p. 19). He later established the first Road Transport Administration Bureau, in 1960, which took charge of transportation and provided benchmarking for the city's road and transport activities.

In modernizing the transport sector, the Emperor accelerated and deepened its privatization by enabling and incentivizing private agencies and companies to aggressively engage in the provision of public transport services at a competitive price. As a pioneer in the stock in trade, he initiated and organized a share company to run the main public operating company, known as Anbessa City Bus Share Company, in 1945. When a series of student revolts in the 1970s made the company one of the targets of popular dissent, the incoming Derg military regime nationalized the Company and it was subsequently managed under the Freight Transport Agency and Public Transport Corporation. Under this command economy, transportation services were centralized as part of a wider campaign to achieve state control over the development and administration of infrastructure, which continued for nearly two decades.

When national power changed again in the early 1990s, the incoming federalist regime adopted free market economic liberalization policies and as part of this the road transport industry was deregulated in 1992. During this period, the City Administration was for the first time empowered to take ownership and management of the only public transport company, Anbesa Bus Enterprise, which has created a substantial financial strain. Since 2013, the city's transportation system has received special attention by the mayor's office, including promises to undertake various institutional reforms.

\section{CHARACTERIZATION OF TRANSPORT GOVERNANCE REFORM PROCESS}

Public Sector Reforms (PSR) are initiated by external motivation required a departure from its old traditional method of running an administration (Fatile et.al, 2010). Usually, impetus for such reforms comes not only from the public administration itself but also from local stakeholders outside and inside the public sector (Schacter, 2000). PSR, or Civil Service Reform (CSR), attempts to change institutions and the way they function (Joshi, A. \& Carter, B. , 2015, p.5).

Depending on attribution, there are many factors considered in the assessment of transport governance reforms. However, this paper considers only two major factors that determine the success of the reforms: political commitment and institutional capacity (Levy, 1993 and Morrisey 1995). Political commitment is a central pillar in delivering on a desired public service reform, whether under democratic or authoritarian political regimes (Morrissey, 1995). Generally, the absence of political commitment is considered to be a common explanation for most public sector institutional (or 'governance') reform failures (Scott, 2011, p.18). As a major driver of reform, political will must be available from the inception of the reform process to when implementation is in its infancy (MUE 25, 2009). Joshi, A. \& Carter, B. (2015) argue that political commitment should be understood in terms of the incentives and disincentives it provides for such reforms. The generation of political will requires the involvement of major political groups, stakeholders and public participation in vigorous debate, leading to a final approval of the reform by a city council or cabinet. A political commitment is not static, it fluctuates and can be influenced by external actors and factors; preparation for the approval of the reform, such as lobbying, should start long before a reform draft is ready for review and discussion (MUE25, 2009, p.1).

Brinkerhoff (2007, p.115,) identifies six main indicators to measure the role of political commitment and ownership in PSR: a) whether the reform motivation is external or internal, b) whether domestic actors have been the driving force behind assessing policy options, outcomes and costs/benefits, c) the extent of consultation with stakeholders; d) public commitment and allocation of resources; e) continuity of effort and commitment of resources and planning for the long term; and f) whether processes for adaptation and learning have been established. In Table 2, the indicators are used to examine the Addis Ababa transport governance reform.

The second factor under examination in this paper is institutional capacity. The concept of institution is generally taken to refer to the rules and norms delimiting and guiding human behavior and social interactions, with obvious relevance to development processes (Morrissey, 1995 p.638). Therefore, institutional capacity involves "the efficiency and adaptivity of the political and economic systems, while institution building encompasses changing political and economic relationships" as part of a reform process (Morrissey, 1995 p.638). Institutions ensure proper resource allocation and ultimately the exercise of power within the state bureaucracy (Joshi, A. \& Carter, B. 2015, p.4). Sometimes, the term "institution" is confused with the term "organization". They are not the same; if institutions can be defined as the "rules of the game", organizations are how we structure ourselves to play' (DFID, 2003a, p. ii). 
This paper customized a general reform assessment framework used by Levy (1993) and Morrissey (1995, p. 639) focusing on the "political commitment to reform" and "institutional capacity to implement" prerequisites for successful reform programs, as shown on Table 1. It is applicable to any PSR assessment and assists us to analyze the overall reform process in the context of institutions and political willingness to alter them through specific application, mostly via administrative capacity.

Table 1 Locating options for urban transport reforms

\section{Political Commitment to Reform}

\begin{tabular}{|c|c|c|c|}
\hline & & $\begin{array}{c}\text { Low } \\
\text { (Conflict, Weak Intent) }\end{array}$ & $\begin{array}{c}\text { High } \\
\text { (Consensus, Intent) }\end{array}$ \\
\hline & $\begin{array}{c}\text { Low } \\
\text { - (Narrow, Simple) }\end{array}$ & $\begin{array}{l}\text { I } \\
\text { Limited prospect for } \\
\text { reform }\end{array}$ & $\begin{array}{l}\text { II } \\
\text { Promote liberalization and } \\
\text { dismantling }\end{array}$ \\
\hline $\begin{array}{l}\text { Institutional } \\
\text { Capacity to } \\
\text { Implement }\end{array}$ & High & $\begin{array}{l}\text { III } \\
\text { Promote roundabout } \\
\text { reform }\end{array}$ & $\begin{array}{l}\text { IV } \\
\text { Abundant menu of viable } \\
\text { policies }\end{array}$ \\
\hline
\end{tabular}

Source: Combination of Morrissey 1995) and Levy (1993)

As Table 1 shows, when both factors are low, prospects for reform are limited; when both are high, many reforms are possible. Levy (1993) argues, in quadrant III, that when political will is low, but capacity is high, "roundabout reform" can be promoted to bring positive changes without creating immediate losers. Importantly, such reform dynamics can generate positive political support. Where when commitment is high but capacity low, then the appropriate reform can be dismantling all non- essential steps toward improving administrative efficiency. This might include both organizational structure change and overall bureaucracy revisiting.

A reform could be in one of the four policy environment/quadrants. Quadrant IV indicates optimal reform outcomes, where innovation and effective reforms can be successfully implemented.

\section{Quadrant I (Neither political desire nor capacity)}

When an institution has neither a political will nor capacity, then all reform attempts might not provide the desired result. This means the policy platform or environment is not conducive to bring feasible public service reform.

2. Quadrant II (high political commitment but low capacity)

In such scenario, a reform is feasible and incremental, i.e. reforms are gradually implemented with a limited scope. The political commitment provides fertile ground to exercise innovation and focusing on the capacity building might assist the constraint to be relaxed. In this case, the appropriate reform is dismantling all that is not essential as a step toward improving administrative efficiency.

3. $\quad$ Quadrant III (low political commitment but high capacity)

Feasible reform is possible, and the achievements could be gradual and incremental in nature, but it might not be that innovative. In such scenarios, roundabout reforms are promoted to bring positive changes without creating immediate losers.

4. Quadrant IV

This should be the ultimate goal of any reform where both innovative and effective reforms could be successfully implemented.

Levy (1993) argues that moving from left to right quadrants means the political commitment increases. If the reform is more desirable, politicians might go beyond their desire to implement reform policies by creating coalitions with opposition members who are in favor.

Generally, institutional reform often involves organizational reform and incorporates two major changes; institutional (formal and informal) as well as organizational change (see Figure 1). These changes are necessary as rules, norms and regulations are implemented, shaped and changed by people and organizations (Joshi, A. \& Carter, B. 2015). The process of institutional reform is a series of steps, starting with analysis and diagnosis of the overall institutional framework and the organization in its 
institutional context, followed by design, and ending with monitoring and evaluation (DFID, 2003b). New PSR reforms usually adhere to lessons drawn from previous experience of public service reforms, such as decentralization, policy setting, policy formulation, policy coordination and institutional change in both formal and informal institutions (Joshi, A. \& Carter, B., 2015, p.5).

Figure 1 Public Sector Governance Reform

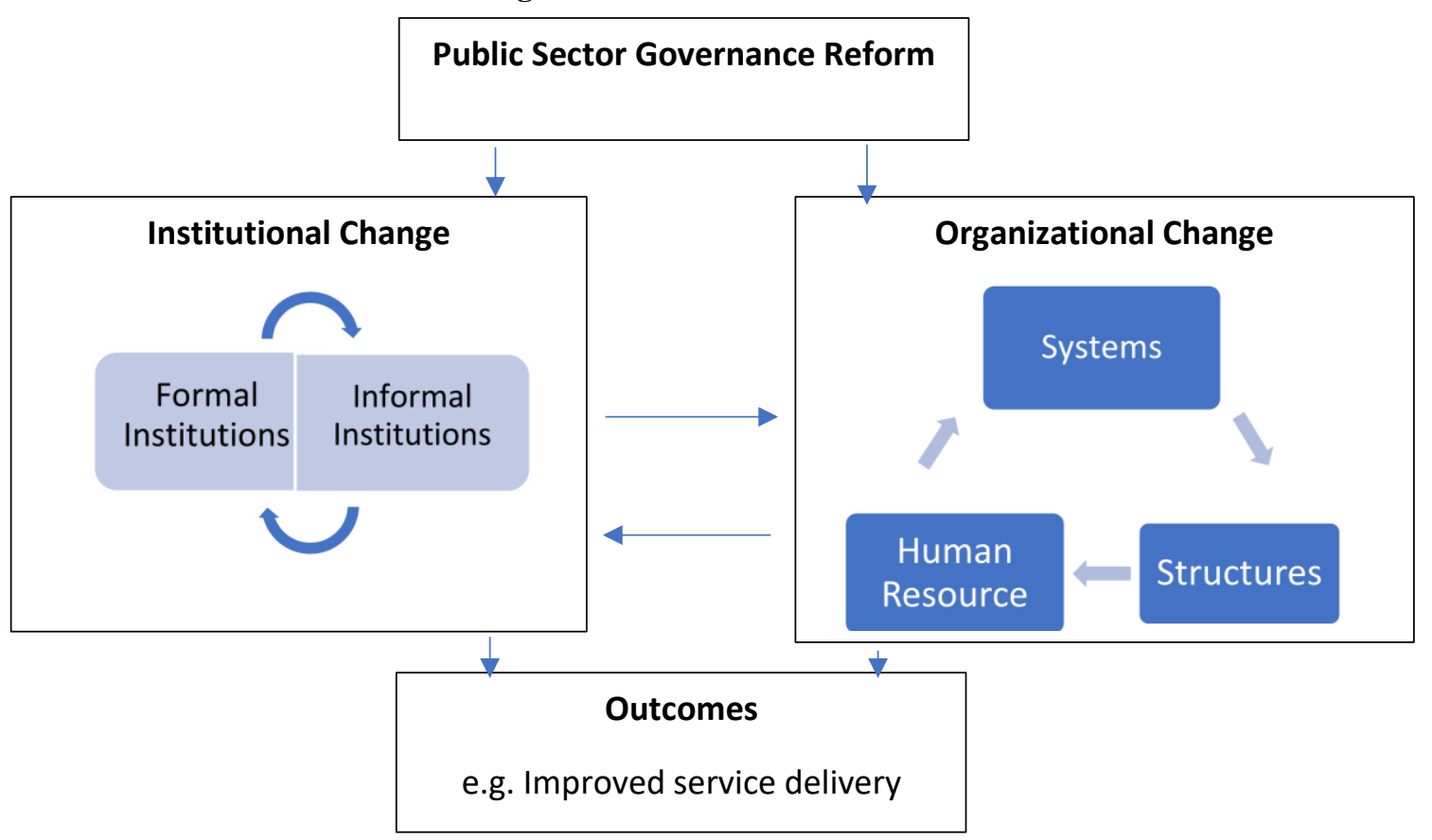

Source: Joshi, A. \& Carter, B. (2015) adopted from DFID, 2003a, P.12

\section{ADDIS ABABA ROAD AND TRANSPORT BUREAU REFORM}

Recent Ethiopian public sector governance reform attempts are home-grown and supply-driven reforms, and have enjoyed high political commitment and ownership. In particularly, the second generation PSR have been seriously undertaken and were aimed at decentralizing decision-making power and narrowing the capacity differences in the bureaucracy by placing effective top-down performance discipline as well as bottom-up accountability mechanisms (WB, 2013).

Following the second PSR, in December 2014, Addis Ababa City Administration Cabinet approved the new transport reform that dissolved and dismantled Addis Ababa Road and Transport Bureau (AARTB) into three new autonomous bodies; the Traffic Management Agency; Public \& Fright Transport Authority; and Drivers \& Vehicles Inspection \& Control Authority, which all are accountable to AARTB.

Before the reform was approved, Mayor Diriba Kuma assigned Dr. Solomon Kidane, an electrical engineer by training, to lead the urban transport transformation/ reform by establishing the Transport Program Management Office (TPMO) with a mandate to coordinate the work of various transport projects and programs as well as to propose new remedial solutions in the case of discovering new challenges. The Program Office was initially established for ten years to help the City Transportation reforms stand on its own feet. The office is run by a board of governors, chaired by the mayor that includes politicians, practitioners, and university academics.

In 2013, TPMO conducted a scoping study to identify and prioritize the key intervention areas by examining the political language, the language of the city dwellers ${ }^{3}$, from the random opinion survey. The result of the assessment identified and ranked the top transport challenges as, first, inadequate public transport services; second, poor traffic management; third, congestion; and fourth, road safety problems. Therefore, based on priorities, TPMO drafted a policy reform plan focused on five pillars which aimed to narrow the gap between policy and implementation; a) development of strategic plans and standards that sustainably augment the current and future transport challenges of the City; b) institutional capacity building; c) project coordination and integration among different stakeholders and within the bureau; d) creating a system of sustainable operation of transport systems and services of the City; e) infrastructure development. The necessity of the reform was also to address some complex political and social contests including corruption, patronage, and political capture according to the General Manager of AARTB (reference?).

${ }^{3}$ Interview with Dr. Solomon Kidane, Transport Bureau head and former TPMO G/ Manager, June 5, 2017 


\subsection{POLITICAL COMMITMENT TO REFORM}

Any Public Sector Reform needs to take politics seriously and move from "thinking politically" to "working differently" (Menocal, 2014, Joshi, A. \& Carter, B. 2015). As shown on Table 2, this papers adopted Brinkerhoff's (2007, p. 115) framework to measure the role of political commitment in the Addis Ababa transport governance reform. The reform was introduced based on problem-driven motivations, consequences of both internal and external pressures. In particular, the city dwellers' demands for better service delivery was a primary driver. However, the reform didn't involve domestic stakeholders - such as opposition political parties, civic institution, private transport operators, taxi associations, community leaders, city residents, and trade and professional associations - during the inception or design stages. Little space was given to informal institutions such as the paratransits in the reform design, even though they cover $40 \%$ of the total mobility in the city. This is partially because the ruling political party (EPRDF) favours firm government control over-if not direct owenership of - all economic activity.

Thus, despite the momentum created by demand from the public and the commitment to quick implementation by the top political leadership, stakeholder consultations were limited by the top-down decision-making approach of the government as well as a culture of limited wider discussion.

On the other hand, because of the mayor's political commitment, the overall financial resource allocation for the transport bureau increased tremendously (the annual budget has jumped from USD 2,608,695 to USD 56,521,739 during what time period?) ${ }^{4}$. However, following this abrupt budget increase, widespread practices of nepotism and rampant corruption undermined the transformation drive of the City Administration. Even though the dominant political philosophy of the ruling party—of which the mayor is an Executive Committee member-doesn't entertain the role of individuals in initiation of policy reform, his personal commitment to bring about change in the transport sector has motivated him to boldly design a reform package and convince the party leadership to buy it.

Table 2 Measuring Factors for Political Commitment in a Reform

\begin{tabular}{lllll} 
Measuring $\begin{array}{c}\text { Factors } \\
\text { Political Commitment }\end{array}$ & for & \multicolumn{2}{c}{ Measurement } & Remark \\
\cline { 3 - 4 } & & High & Medium low &
\end{tabular}

1 Motivation-External

Pressure from the public for a better service was the main reason also meant to attract financers/donors

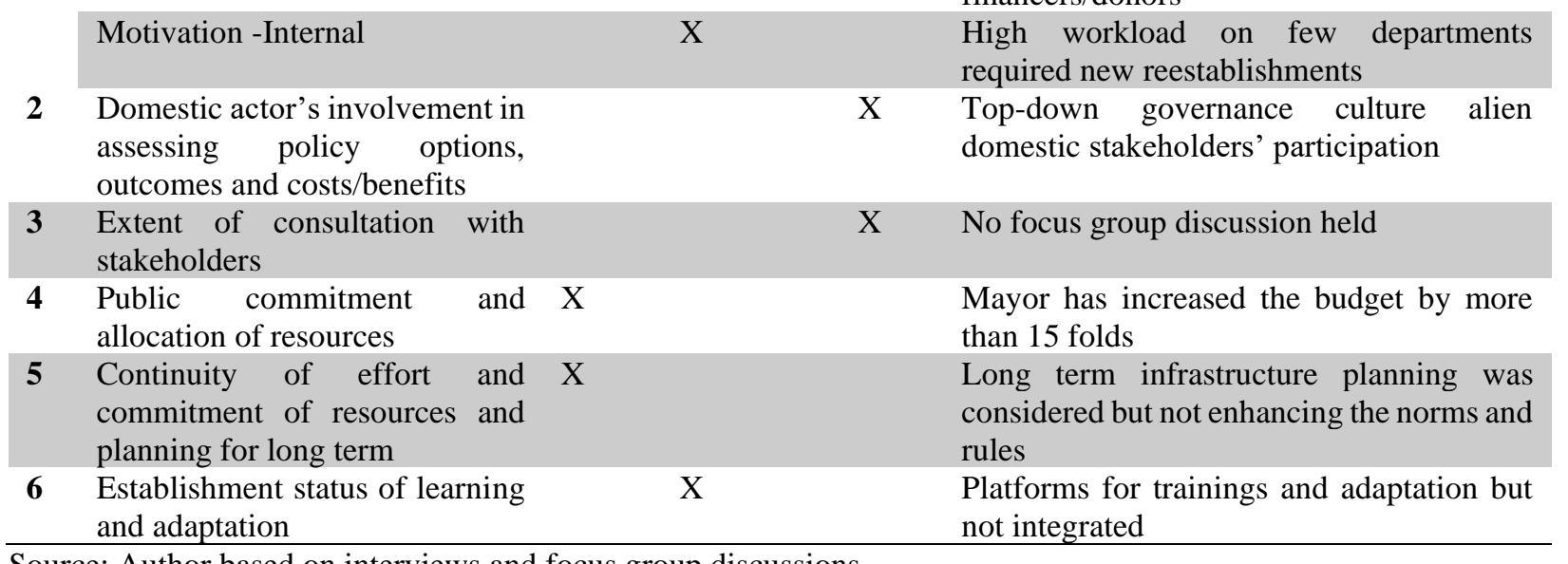

Source: Author based on interviews and focus group discussions

\subsection{The Institutional Capacity-to-Implement}

The transport governance reform of the Addis Ababa City was focused on establishing new offices and reshaping the overall organizational structure, rather than improving institutional capacity to provide incentives in a way that shapes the behavior in the bureau. This has been the main pitfall in consecutive reform attempts by the city administration. Since the mayor has established the Transport Program Project Office without being professionally advised as to how that office should by managerially and structurally constituted, the organization seems to be navigated in a haphazard way. Initially the office was assumed to take up the overall responsibility for leading and managing the urban transport in a way that overlaps and redundant with the mandates of AARTB. In addition, there were some flip-flops, as to whether the office be a project management or program management and

\footnotetext{
${ }^{4}$ TPMO annual report 2015/16
} 
some critical issues are handled as the come along. Particularly, there is a widespread confusion in regulation and planning that ultimately causes coordination problems among different departments.

In 2014, the program office brought a draft of the reform study to the management board that framed the above-mentioned issues. Therefore, the draft study strongly suggested reorganizing the Transport Bureau and establishing new agencies mandated to conduct a specific task, as shown in Figure $2 \& 3$. However, the reorganization of the Bureau was not as smooth as anticipated; the implementation process had many challenges, such as conflicts of interest among agencies within the bureau. For example, the Road Authority needs the freedom which it previously enjoyed. On top of this, the availability of adequate human resources to fill the ambitious organizational structure was another capacity challenge. Notably, the country's $\backslash$ higher education system does not produce the sufficient experitse in the fields of transportation, such as planners, engineers, transport economics and management.

Figure 2 Pre-reform organizational structure

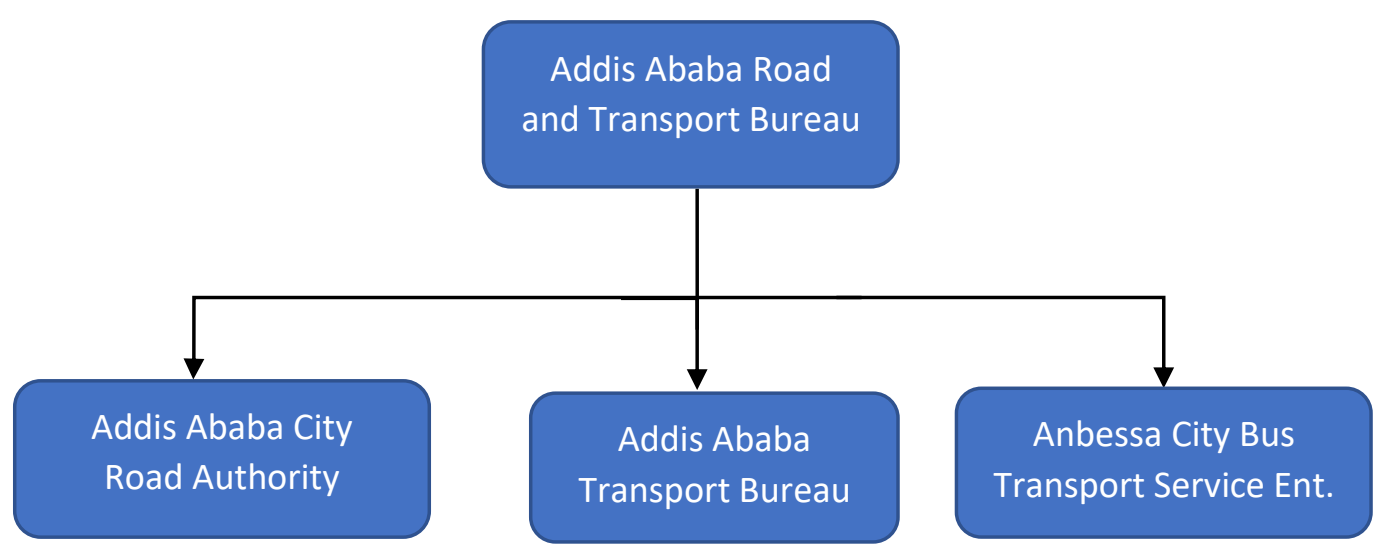

Figure 3, Post reform organizational structure

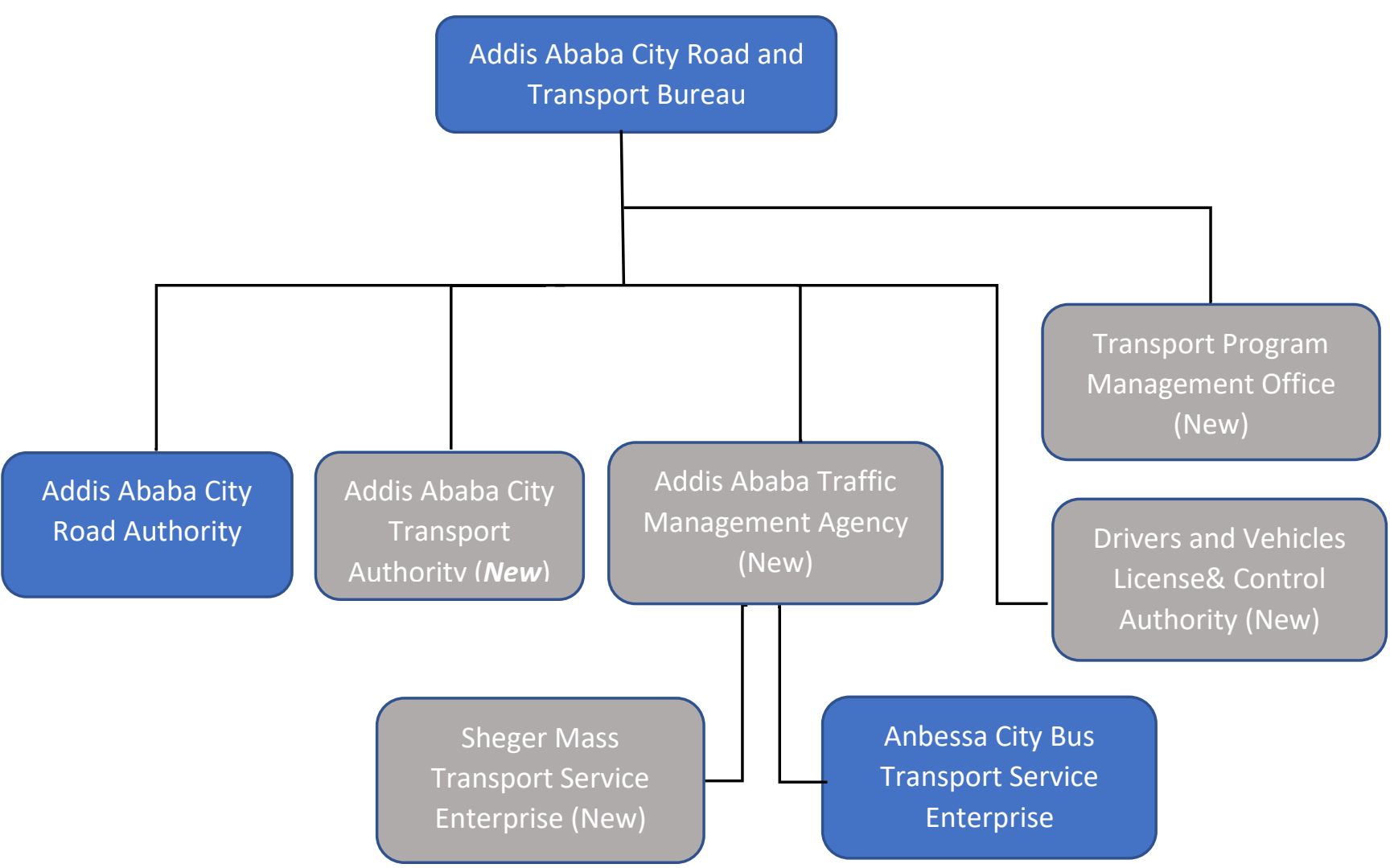


Regarding institutional stability, what is being regularly observed is impermanence. Reshuffling and staff turnover including in leadership is frequent and common. For example, the top management of the transport department has been changed four times in a matter of five years (2012-2017). On top of this, regular shake ups of the management and other key staff has resulted in misunderstandings and flaws in the execution and management of policy decisions, contributing toward the prevalence of uncertainty and unpredictability. In addition, employees' salaries and compensation are not designed differently from that of the public service, which is often criticized for not competitively reflecting the opportunity rate of return of the labor market and which is said to push many of the young professionals to migrate frequently and in mass. Furthermore, salary scale differences among the institutional structures created by the reform has exacerbated ambiguity and draws unnecessary competition, particularly between the bureau and TPMO.

To bridge the technical gaps in institutional capacity, the mayor could consider establishing a professional counseling committee to provide high-level advice, research-based recommendations and to develop strategic planning for the City Administration and the Bureau on where and how to intervene in areas that could address the day-to-day transport challenges. At the same time, this should engage in capacitation of various stakeholders in the transport sector. In addition, the technical committee could be empowered to initiate solutions for long-term effects on projects that are anticipated to have long-term impact

\subsection{Reform in Policy Enviornments of High Political Commitment and Low Institutional Capacity}

Therefore, the transport problems in Addis Ababa are not caused by a lack of technical knowledge or financial resource shortages; rather, they are an outcome of long-term negligence of the transport policy direction as well as its management efficiency. Despite high political commitment from the leadership, the overall reform implementation focused more on quick-fixes rather than initiating sustainable mitigation measures to the transport challenges the city is encountering.

To meet this end, different reform strategies are required for different policy environments. Addis Ababa Transport governance reform falls in quadrant III, as shown on Table 1, which has relatively high political commitment with low institutional capacity. Therefore, in such cases, even if the capacity is low, limited incentives can be introduced to immediate stakeholders who could shoulder the main transport problem, such as the para-transits and private-public operators. For example, revisiting the incentives provided for public transport operators, which has been the main bottleneck since the nationalization of the private public bus operator in 1974, can be accommodated. In such cases, a more simplified incentive structure for specific transport services is advisable and this will assist to develop the institutional capacity of the bureau to implement broader-based reforms and deliver greater transport service efficiency.

\section{CONCLUSION}

Political commitment and building institutional capacity are pre-requisite for any reforms that aim to bring good governance, economic growth and social stability. This research draws three main conclusions. First, the transport governance reform didn't allocate enough time for planning, design and execution measures that include identifying institutional capacity/incentives and administration capacity gaps. Second, given the weak institutional capacity in the policy environment, targeting specific transport service areas and piloting reform in those is advisable instead of implementing wide and large-scale reforms. Third, engaging the main stakeholders in every policy process is necessary to enhance its implementation.

\section{REFERENCES}

[1] Ajay Kumar and Fanny Barrett, 2008, Africa Infrastructure Country Diagnostic Stuck in Traffic: Urban Transport in Africa, World Bank and the SSATP

[2] DFID. (2003a). Promoting institutional appraisal and development (Guidelines for DFID). London: Department for International Development. Emmenegger, 2012, p.16

[3] Fatile, Jacob Olufemi and Adejuwon, Kehinde David, 2010, PUBLIC SECTOR REFORM IN AFRICA: ISSUES, LESSONS AND FUTURE DIRECTIONS, Journal of Sustainable Development in Africa (Volume 12, No.8, 2010) ISSN: 1520-5509

[4] Ken Gwilliam, 2011, Africa's Transport Infrastructure, Mainstreaming Maintenance and Management, World Bank

[5] Lall, Somik Vinay, J. Vernon Henderson, and Anthony J. Venables. 2017. “Africa's Cities: Opening Doors to the World.” World Bank, Washington, DC.

[6] Mark Schacter,2000, Public Sector Reform in Developing Countries Issues, Lessons and Future Directions, Institute On Governance Ottawa, Canada www.iog.ca, Policy Branch Canadian International Development Agency December, 2000

[7] Matia 2016. ( history )

[8] MUE25, 2009, Political Commitment, Managing Urban Europe 25 Sustainable Factors for Cities, http://ec.europa.eu/environment/life/project/Projects/index.cfm?fuseaction=home.showFile\&rep=file\&fil=CHAMP_guide_4.pdf

[9] Mutahaba, G. \& Kiragu, K. (2002). Lessons of International and African Perspective on Public Service Reform: Example from Five African Countries African Development, 27(3\&4), 48-75.

[10] Scott, Z. (2011). Evaluation of Public Sector Governance Reforms 2001-2011. Literature Review: Oxford Policy Management

[11] Transport Research Laboratory (TRL), 2002, Scoping study Urban mobility in three cities, World Bank SSATP

[12] Temesgen Aklilu ,2007, THE ROLE OF THE TRANSPORT SECTOR IN ETHIOPIA'S ECONOMIC DEVELOPMENT, Ethiopian Economic Association/Ethiopian Economic Policy Research Institute (EEA/EEPRI),Vol. 9 No.4, 2007

[13] World Bank, April 26 2013, Federal Democratic Republic of Ethiopia Public Sector Reform Approach, Building the Development State-A Review and Assessment of the Ethiopian Approach to Public Sector Reform 